Check for updates

Cite this: RSC Adv., 2017, 7, 52133

\title{
A perspective on diverse adsorbent materials to recover precious palladium and the way forward
}

\begin{abstract}
Shivani Sharma, A. Santhana Krishna Kumar (D) $\dagger$ and N. Rajesh (iD *
The removal and recovery of precious noble metals is noteworthy in a variety of applications. The need to recover these precious metals is associated with their high cost and other environmental impacts. The Nobel Prize conferred to Suzuki, Heck and Negishi in 2010 has underlined the remarkable significance of palladium as a catalyst in several important transformations. Palladium is one such platinum group noble metal that finds diverse applications in the automobile industry, electronics, jewelry, pharmaceutics, catalysis, etc. Therefore, the recovery of palladium has acquired importance. Methods such as liquidliquid extraction and adsorption using biopolymers, polymeric resins, carbonaceous materials and silica based materials are discussed based on their removal efficiency, adsorption capacities, regeneration and other parameters. The review looks at a perspective based on the applicability of certain important adsorbents employed in recent years pertaining to the removal of palladium from aqueous solution, spent catalysts and industrial wastes.
\end{abstract}

Received 12th September 2017 Accepted 31st October 2017

DOI: $10.1039 / \mathrm{c} 7 \mathrm{ra10153h}$

rsc.li/rsc-advances

indicate that palladium can go through plant roots and ultimately penetrate the food chain. ${ }^{5}$ The scarcities of precious metals and rapid industrial development have seen the emergence of several new techniques for recovering this valuable metal. ${ }^{6-8} \mathrm{~A}$ broad series of biosorbents and non-conventional adsorbents have gained marked attention for their ability to remove heavy metals from wastewater. ${ }^{9}$ Methods such as ionexchange, solvent extraction, coagulation, photocatalytic degradation, membrane separation and adsorption are known for their efficiency in the removal and recovery of heavy metals. ${ }^{10-12}$ Adsorption is well-known for its significance towards the recovery of platinum group metals (PGM's) at very low concentrations with high efficacy. ${ }^{13,14}$ This review presents an outlook on the removal (Fig. 1) and recovery techniques for

Department of Chemistry, Birla Institute of Technology and Science, Pilani-Hyderabad Campus, Jawahar Nagar, Shameerpet Mandal, R.R. District, Hyderabad 500 078, India.E-mail: nrajesh05@gmail.com; Fax: +91 40 66303998; Tel: +91 4066303503 $\uparrow$ Present address: Department of Chemistry, National Sun Yat-sen University, Kaohsiung 804, Taiwan.
Shivani Sharma obtained her M.Sc Chemistry from Himachal Pradesh University, Shimla, India and M.Phil(Chemistry) from Shoolini University, Solan, India. She completed her Ph.D. at Birla Institute of Technology and Science (BITS Pilani), Hyderabad campus, India in 2017 relating to the removal and recovery of precious palladium from spent catalysts using diverse adsorbent materials. Her research interests focus on separation techniques and analytical method development and validation.

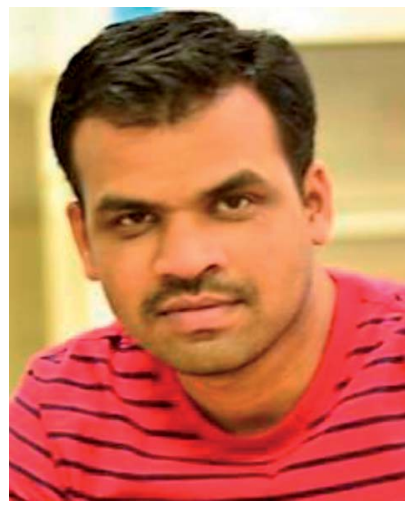

A. Santhana Krishna Kumar obtained his Ph.D. from Birla Institute of Technology and Science (BITS Pilani), Hyderabad campus, India in 2014. He has studied the application of variety of adsorbent materials involving biopolymer-clay and ionic liquid interactions for the detoxification of chromium and mercury. Currently, he is a post doc at National Sun Yat Sen University, Taiwan. His research interests focus on the development of suitably customized adsorbents for heavy metal removal from industrial effluents. 


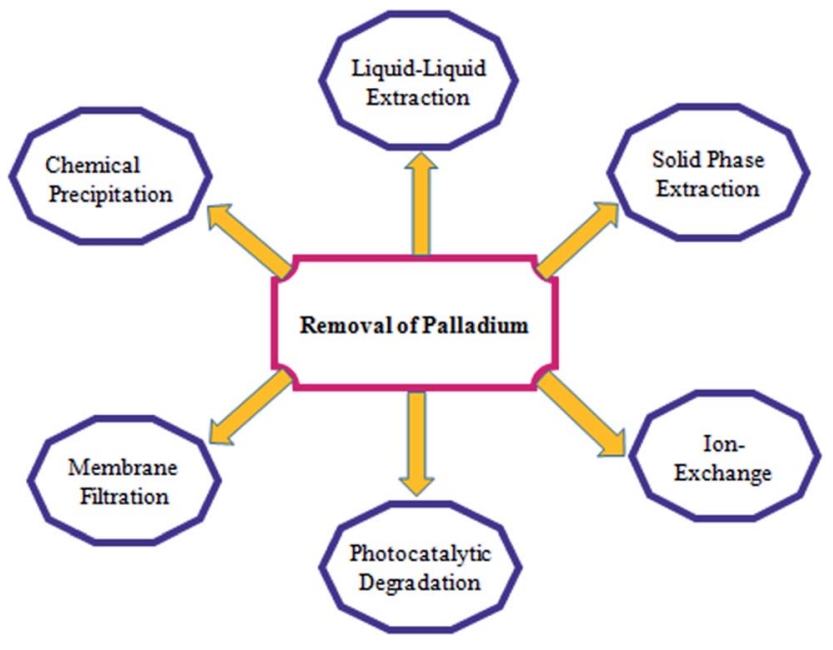

Fig. 1 Methods for removal of palladium.

palladium and its future perspectives. Techniques such as liquid-liquid extraction and solid phase extraction using biopolymers, polymeric resins, carbonaceous materials and silica based materials are compared with regard to their removal efficiency, regeneration, adsorption capacity and other characteristics. The recovery of palladium from spent catalyst and liquid waste is also discussed in this review. Considering the merits and demerits associated with various methods, the way forward towards devising improved methodologies is also suggested from a greener perspective.

\section{Palladium chemistry}

The occurrence of palladium in the Earth's crust is around 1 to 10 parts per trillion. Palladium with atomic number 46 is positioned in Group 10 (VIII B) of the periodic table. It is a soft silvery-white metal bearing resemblance to platinum. With a low density $\left(11.9 \mathrm{~g} \mathrm{~cm}^{-3}\right.$ at $\left.20^{\circ} \mathrm{C}\right)$, it has the lowest melting point $\left(1555^{\circ} \mathrm{C}\right)$ among the platinum group metals. It is soft and

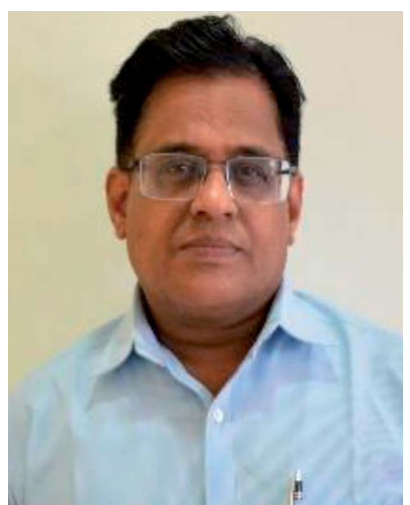

N. Rajesh obtained his Ph.D. from Indian Institute of Technology (IIT), Madras, India. He is currently a full professor at Birla Institute of Technology and Science, (BITS) Pilani, Hyderabad campus, India. He is involved in teaching and research for the past 20 years. He is a fellow member of the Royal Society of Chemistry (FRSC). His research interests include development of greener sorbents for the effective removal of chromium, mercury, lead, palladium, europium etc. His group is engaged in the development of biopolymer, graphene and clay based adsorbents for precious metal recovery and environmental remediation. ductile when annealed and appreciably increases its toughness when cooled. Palladium dissolves slowly in concentrated $\mathrm{HNO}_{3}$, $\mathrm{H}_{2} \mathrm{SO}_{4}$ and $\mathrm{HCl}^{15}$

Palladium exists in its common oxidation states as $0,+2$ and +4. Palladium is a soft acid and forms relatively strong complexes with soft bases/ligands having sulfur donor atoms. $^{16,17}$

At normal temperatures, palladium would not react with oxygen and hence does not tarnish in air. However, at $800{ }^{\circ} \mathrm{C}$, a layer of palladium(II) oxide is formed, which tarnishes in moist atmosphere containing sulfur. ${ }^{18}$

In many palladium catalyzed reactions, palladium(II) chloride is the major starting material. It is used for preparing heterogeneous catalysts such as $\mathrm{Pd} / \mathrm{BaSO}_{4}, \mathrm{Pd} / \mathrm{C}$ and $\mathrm{PdCl}_{2} / \mathrm{C}^{.19}$ With triphenylphosphine $\left(\mathrm{P}\left(\mathrm{C}_{6} \mathrm{H}_{5}\right)_{3}\right)$, palladium forms bis(triphenylphosphine)palladium(II) dichloride, which serves as a very useful and important catalyst. ${ }^{20}$

$$
\mathrm{PdCl}_{2}+2 \mathrm{PPh}_{3} \rightarrow \mathrm{PdCl}_{2}\left(\mathrm{PPh}_{3}\right)_{2}
$$

Reduction of bis(triphenylphosphine)palladium(II) dichloride with hydrazine and phosphine gives tetrakis(triphenylphosphine)palladium(0). ${ }^{21}$

$$
\begin{aligned}
2 \mathrm{PdCl}_{2}\left(\mathrm{PPh}_{3}\right)_{2}+4 \mathrm{PPh}_{3}+5 \mathrm{~N}_{2} \mathrm{H}_{4} \rightarrow \\
2 \mathrm{Pd}\left(\mathrm{PPh}_{3}\right)_{4}+\mathrm{N}_{2}+4 \mathrm{~N}_{2} \mathrm{H}_{5}^{+} \mathrm{Cl}^{-}
\end{aligned}
$$

Palladium is capable of forming stable chloro-complexes such as $\mathrm{PdCl}^{+}, \mathrm{PdCl}_{2}, \mathrm{PdCl}_{3}{ }^{-}$and $\mathrm{PdCl}_{4}{ }^{2-}$ in acidic chloride solutions. The common square planar species found for palladium in chloride medium is $\mathrm{PdCl}_{4}{ }^{2-}$, although a dimeric species, namely $\mathrm{Pd}_{2} \mathrm{Cl}_{6}{ }^{2-}$ (ref. 22) is also found. At $0.1 \mathrm{~mol} \mathrm{~L}^{-1}$ chloride ion concentration and higher, the predominant species in solution is $\mathrm{PdCl}_{4}{ }^{2-}{ }^{23}$ The stability constant values of these complexes are known ${ }^{24}$ through the following equations:

$$
\begin{gathered}
\mathrm{Pd}^{2+}+\mathrm{Cl}^{-} \rightarrow[\mathrm{PdCl}]^{+}, K=10^{6} \\
\mathrm{Pd}^{2+}+2 \mathrm{Cl}^{-} \rightarrow \mathrm{PdCl}_{2}, K=10^{10} \\
\mathrm{Pd}^{2+}+3 \mathrm{Cl}^{-} \rightarrow\left[\mathrm{PdCl}_{3}\right]^{-}, K=10^{13} \\
\mathrm{Pd}^{2+}+4 \mathrm{Cl}^{-} \rightarrow\left[\mathrm{PdCl}_{4}\right]^{2-}, K=10^{16}
\end{gathered}
$$

From the values of stability constant, it is understood that the most stable form for $\mathrm{Pd}(\mathrm{II})$ ion in hydrochloric acid medium is $\left[\mathrm{PdCl}_{4}\right]^{2-}$.

\section{Toxicity of palladium}

Palladium has relatively lower toxicity as compared to other heavy metals and is weakly absorbed by human body if ingested. Some plants such as water hyacinth are known to be affected by quite low concentrations of palladium salts. However, other plants can endure it, even though tests indicate that when the 
levels are higher than $0.0003 \%$, their growth is inhibited. Higher dosage of palladium could be detrimental and tests on rodents recommend that it can be carcinogenic. Nevertheless, there is no direct confirmation that palladium could have any adverse effects in human body. ${ }^{25}$ However, if appropriate procedures for recovery are not developed, it could lead to the accretion in the environment and transported through roots of plants and thereby finally enter the food chain. ${ }^{5}$

\section{Applications of palladium}

The Nobel Prize jointly awarded to Heck, Suzuki and Negishi in 2010 has brought more attention to explore and understand the potential applications of palladium. ${ }^{26}$ Palladium finds extensive utility in industrial technologies and research laboratories due to its specific physicochemical properties such as high resistance to acids, heat and corrosion. ${ }^{27,28}$ The demand for palladium is ever increasing especially in catalysis, electronics industries (printed circuit boards), and alloying component and as a whitening agent in jewelry. ${ }^{2,3,29,30}$ Palladium is also used in surge-resistor networks that protect telecommunications equipment from damage due to high voltage. The catalytic properties of platinum group metals are utilized in developing automotive emission control catalysts. Palladium nanostructures and $\mathrm{Pd}$ (II) complexes have gained interest in the last decade in a number of applications including catalysis, medicines (prostate cancer, choroidal melanoma brachytherapy) and electrical equipments. ${ }^{31-34}$ The collective catalytic properties of PGM's are very significant in automotive exhaust catalysts. ${ }^{35,36}$

\section{Methods for separation and recovery of palladium}

The typical analytical methods involve pretreatment methods (alkaline fusion, ashing, wet digestion, microwave-assisted decomposition) followed by proficient enrichment and separation from complex interferences and instrumental analysis of the target analyte. ${ }^{37}$

Several methods are in vogue to remove palladium from aqueous solutions, industrial effluents, high level waste etc. Common methods include solvent extraction, membrane separation, ion exchange, reverse osmosis, precipitation and adsorption..$^{38-44}$ Each of these has its own advantages and disadvantages.

Liquid-liquid extraction technique has long been recognized in analytical chemistry and many extractants have been explored for the separation of platinum group metals. Recovery of $\mathrm{Pd}(\mathrm{II}$ ), $\mathrm{Au}$ (III) and Pt(Iv) using ionic liquid Aliquat-336 (ref. 45) and phosphonium-based ionic liquid such as Cyphos IL 101 $\left(\left[\mathrm{P}_{66614}\right]^{+} \mathrm{Cl}^{-}\right)^{46}$ as well as $N, N^{\prime}$-dimethyl- $N, N^{\prime}$-dicyclohexylthiodiglycolamide ${ }^{47}$ have been recently reported. Amide derivatives, ${ }^{48}$ sulfide containing monoamides, ${ }^{49}$ dithiodiglycolamide ${ }^{50}$ and particular thiodiglycolamide derivatives ${ }^{51,52}$ have also been proposed for the extraction of palladium. Reddy et al. have reported the solvent extraction technique to separate and recover Pd and Pt from leach liquid of the spent automobile catalyst using LIX 84I (2-hydroxy-5-nonylacetophenone oxime) and Alamine 336 (tertiary amine of mixed tri-octyl/decyl amine) extractants. Leach solution used in this method contained impurities such as $\mathrm{Fe}, \mathrm{Cr}, \mathrm{Mn}$, and $\mathrm{Ni}$ in $3.0 \mathrm{~mol} \mathrm{~L}^{-1} \mathrm{HCl}$ along with Pd and Pt ions. ${ }^{53}$ The separation of Pt and Pd from chloride solution using Alamine 300 (tri- $n$-octyl amine) as an extractant was studied using solvent extraction and the selective stripping was proficient with sodium thiocyanate and sodium thiosulfate for Pt and Pd respectively. ${ }^{54}$ The use of toxic solvents as diluents and low preconcentration factors limits the application of solvent extraction. A more efficient choice to recover palladium is solid phase extraction and adsorption is best suited to recover platinum group metals at low concentrations. ${ }^{13}$ Adsorption is also quite economical and more effective than the solvent extraction methods.

The commonly employed analytical techniques for palladium include inductively coupled plasma atomic emission spectrometry (ICP-AES), inductively coupled plasma mass spectrometry (ICP-MS), atomic absorption spectrophotometry and UV-visible spectrophotometry.

\subsection{Solid phase extraction}

Solid Phase Extraction (SPE) is an efficient separation method for the preconcentration of trace elements and their separation from various sample matrices. ${ }^{55,56}$ It involves the distribution of the analyte between the liquid sample and the solid matrix by adsorption on the surface. SPE consists of two components (a) an inert solid support and (b) a complexing agent impregnated on the solid support. The characteristic of the complexing agent is quite important to decide the selectivity towards a specific metal ion and the solid support dictates the properties such as adsorption capacity, chemical stability and mechanical strength. The method has advantages over other methods in terms of good analyte recovery, higher sample volume treatment, facile adsorption and desorption mechanism, regenerability and clean up procedure. ${ }^{57}$ Biopolymers, resins and carbon based materials as supports can be customized to extract the precious metals effectively from complex matrices. However, when the above adsorbents are chemically modified it yields a higher analyte retention efficiency as well as selectivity towards a desired metal ion. Some representative adsorbent materials and their specific functional groups are given in Fig. 2. These materials involve different mechanisms in the interaction with palladium(II). The probable interaction mechanisms involved in the recovery and regeneration of palladium is given in Fig. 3.

5.1.1 Biopolymers. In recent years, biopolymers have gained prominence for adsorption of heavy metal ions due to their low cost, eco-friendly nature, biodegradability and biocompatibility. ${ }^{58,59}$ Among the biopolymers, cellulose (a polysaccharide with the formula $\left(\mathrm{C}_{6} \mathrm{H}_{10} \mathrm{O}_{5}\right)_{n}$, composed of several $\beta(1-4)$ linked $\mathrm{D}$-glucose units) and chitosan (a nitrogenous polysaccharide consisting of poly( $\beta-1-4)$-2-amino-2-deoxyD-glucopyranose, obtained through deacetylation of chitin) are considered as effective biosorbents because of the presence of functional groups such as amino and hydroxyl showing high 
Cellulose

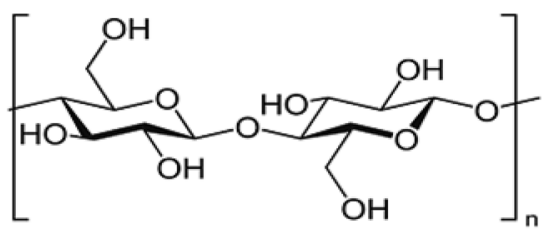

Chitosan

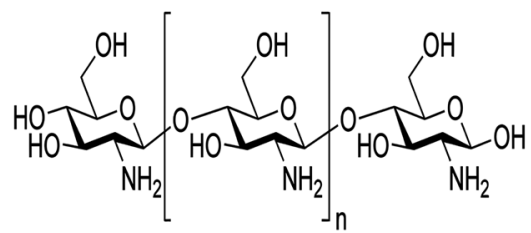

\section{Graphene oxide}

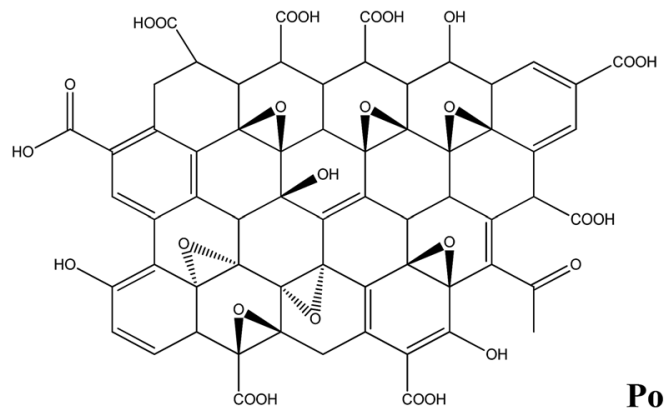

Polystyrene divinyl benzene resin
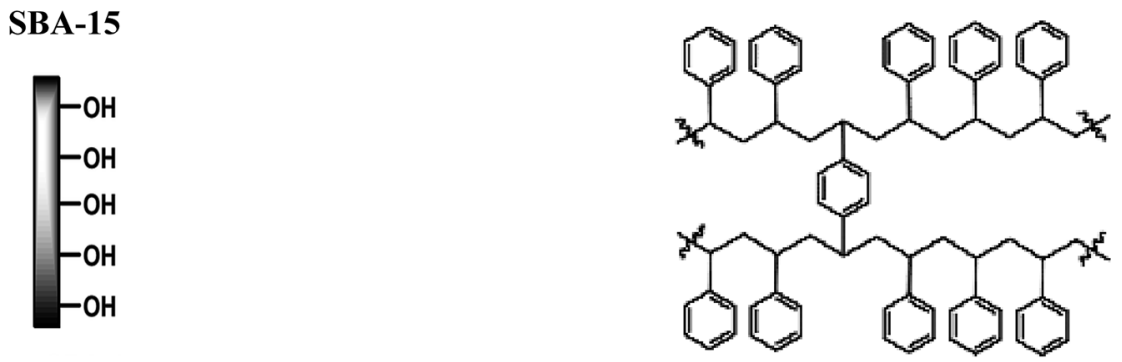

Fig. 2 Adsorbent materials with diverse functional groups.

adsorption for various heavy metals. ${ }^{60,61}$ These biopolymers represent an attractive alternative to other biomaterials due to their physico-chemical characteristics, high reactivity, chemical stability, good chelation behavior and higher selectivity towards heavy metals. Natural chitosan was customized (either physically or chemically) with the aim of enhancing the sequestration

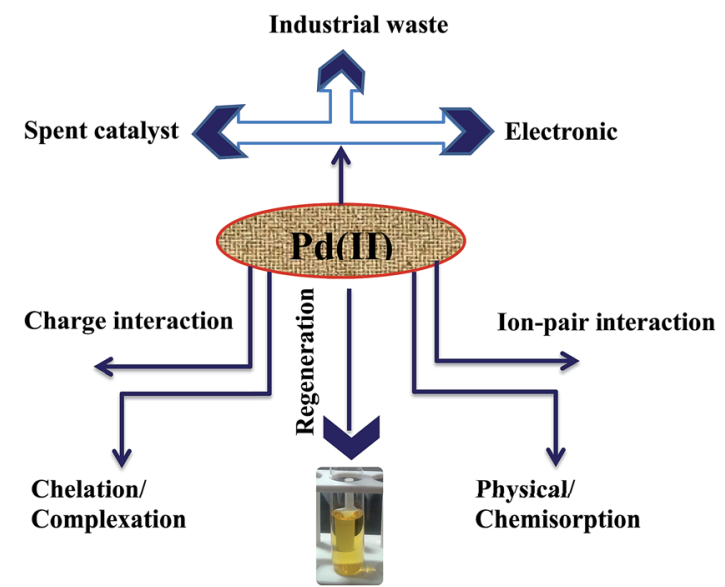

Fig. 3 Interaction mechanism, recovery and regeneration of palladium. of heavy metals. Cellulose and chitosan as such have lower adsorption capacity due to the unavailability of effective binding adsorption sites. Modification (functionalization, grafting, impregnation etc.) of these biopolymers yield desirable properties such as higher adsorption capacity, distribution coefficient, fast sorption kinetics etc. Cross linkers such as ethylenediamine ${ }^{62}$ and epichlorohydrin ${ }^{63}$ are used to modify chitosan for the removal of metal ions. Cross-linked chitosan modified chemically with L-lysine was used to examine the adsorption of $\mathrm{Au}(\mathrm{III}), \mathrm{Pt}(\mathrm{Iv})$ and $\mathrm{Pd}(\mathrm{II})$ from aqueous solutions. ${ }^{64}$ The maximum adsorption capacity for Pd(II) was found to be $109 \mathrm{mg} \mathrm{g}^{-1}$ and thiourea-HCl mixture was used to regenerate the adsorbent. The selectivity for a particular metal ion depends on the nature of complexing agent and the biopolymer. Glutaraldehyde was used for crosslinking chitosan through imine linkage between aldehyde groups of the crosslinker and amine groups of chitosan and this modified sorbent was checked for palladium recovery in acidic medium. ${ }^{65} \mathrm{Pd}(\mathrm{II})$ adsorption onto cross-linked chitosan modified using glycine was also studied, wherein ethyleneglycoldiglycidylether was used to cross-link chitosan biopolymer. ${ }^{66}$ Cross-linking of chitosan with ethylenediaminetetracetic acid ${ }^{67}$ is also very effective for the adsorption of metal ions. Thiourea tailored chitosan microspheres were well efficient to adsorb Pd(II) from aqueous 
solution. ${ }^{68}$ The adsorption equilibrium was well described by Langmuir adsorption capacity of $112.4 \mathrm{mg} \mathrm{g}^{-1}$ and the adsorbent was stable up to 5 cycles using EDTA- $\mathrm{H}_{2} \mathrm{SO}_{4}$ mixture. Ethylenediamine tailored magnetic chitosan nanoparticle was examined to adsorb palladium(II) and platinum(Iv) from aqueous solutions. ${ }^{69}$ Glutaraldehyde cross-linked chitosan/ montmorillonite (CCTS-M) membrane was utilized in the removal of $\operatorname{Pd}(\mathrm{II})$ from aqueous solutions. The maximum capacity of the membrane at $\mathrm{pH} 2$ was as high as $193 \mathrm{mg} \mathrm{g}^{-1} .^{70}$

The adsorption characteristics of diethylaminoethylcellulose sorbent prepared by crosslinking glutaraldehyde using thiourea for the recovery of platinum $\mathrm{Pt}(\mathrm{Iv})$ and palladium Pd(II) ions from leaching solutions was reported. ${ }^{71}$ Aliquat-336 (ionic liquid) impregnated onto chitosan was prepared and studied for the adsorption behavior of Pd(II). The efficiency of adsorption was observed between $\mathrm{pH}$ 3.5-4.0 with a maximum monolayer adsorption capacity of $187.61 \mathrm{mg} \mathrm{g}^{-1} .^{72}$

A genetically engineered protein involving palladium binding peptides and cellulose binding domains in Escherichia coli showed good potential for palladium recovery. The recovery of palladium was observed over a wide $\mathrm{pH}$ with high efficiency. The maximum adsorption capacity of cellulose binding domain was found to be $175.44 \mathrm{mg} \mathrm{g}^{-1} \cdot{ }^{73}$ Sulfur containing ligands were impregnated with biopolymers to study the adsorption of palladium. Sonication ensures a fast and green alternative to prepare the adsorbent and in this regard, 2-mercaptobenzothiazole impregnated cellulose was studied to adsorb palladium effectively. Thiourea was used to regenerate and reuse the adsorbent for 4 cycles and the adsorbent was quite effective to recover palladium from a catalyst. ${ }^{74}$ 2-Mercaptobenzimidazole impregnated chitosan was also studied for palladium adsorption. The classification of $\mathrm{Pd}^{2+}$ as a soft acid makes it able to bind with sulfur and nitrogen donor atoms present in the ligand to form a stable metal chelate through secondary hostguest interaction. Here, the adsorbent was regenerated and reused for 3 cycles using thiourea. ${ }^{75}$ Thiourea, being a sulfur containing ligand complexes effectively with palladium giving a yellow color in the aqueous medium after regeneration.

$\beta$-Cyclodextrin, which is a cyclic torus-shaped oligosaccharide comprised of seven ( $\alpha$-1,4-linked-glucopyranose units) with a lipophilic exterior and an internal hydrophobic cavity is found to be suitable for inclusion and binding of guest compounds. ${ }^{76,77}$ Due to the internal hydrophobic cavity, these macromolecules (CDs) with wide and narrow openings having the secondary and primary hydroxyl groups can encapsulate a large variety of compounds. ${ }^{78}$ This feature was explored in the field of catalysis, pharmaceutics, cosmetics, food, textile industries and environmental remediation. ${ }^{78}$ The interest in modifying chitosan by use of glutaraldehyde has recently increased. Chitosan grafted $\beta$-CD was examined for the selective adsorption in cleaning up industrial effluents ${ }^{79}$ and removal of undesirable food contents. ${ }^{80}$ Cyclodextrin grafted chitosan was recently proven to be very effective resulting in a high adsorption capacity of $202 \mathrm{mg} \mathrm{g}^{-1}$ for palladium. The adsorbent showed good potential to recovery palladium from a simulated high level liquid waste in the presence of diverse ionic constituents. ${ }^{81}$ Regeneration of the adsorbent was accomplished using thiourea. Other than biopolymers, carbonaceous supports also yield good adsorption capacities for adsorbing heavy metals.

5.1.2 Carbon based materials. Novel adsorbents belonging to carbon family such as activated carbon, carbon nanotubes, graphite and graphene oxide have attained substantial prominence in heavy metal remediation. ${ }^{82}$ Graphene-a carbon based material has gained tremendous research interest for its prospective applications since its discovery in view of its high tensile strength and surface area coupled with distinct electrical and thermal conductivity. ${ }^{\mathbf{8 3}, 84}$ Graphene oxide (GO), a derivative of graphene, ensuing from the exfoliation of graphite, bears the oxygen containing functionalities like epoxy, hydroxyl and carboxyl groups ${ }^{\mathbf{8 5}}$ and has a layered structure which makes it appropriate as an adsorbent, showing high adsorption efficiency for various metal ions. ${ }^{86} \mathrm{GO}$ is also known for its utility in other applications such as sensors and catalysts. ${ }^{87}$ Graphene oxide also finds utility in diverse environmental applications. ${ }^{\mathbf{8 8} 89}$ Graphene oxide functionalized with aminothiophenol and its covalent bonded interaction to the palladium nanoparticles through sulfur atom was studied. Here, the GO-aminothiophenol-Pd was electrochemically reduced to graphene oxide. ${ }^{90}$ Chitosan/graphene oxide composites were also used as an adsorbent for the enhanced adsorption of $\mathrm{Au}(\mathrm{III})$ and $\mathrm{Pd}(\mathrm{II}) .{ }^{91}$ Activated carbon and biopolymer modified activated carbon were reported for palladium and platinum removal. Here, activated carbon showed an adsorption capacity of $35.7 \mathrm{mg} \mathrm{g}^{-1}$ (palladium) and $45.5 \mathrm{mg} \mathrm{g}^{-1}$ (platinum), whereas the adsorption capacity using bio-polymer modified activated carbon was enhanced to $43.5 \mathrm{mg} \mathrm{g}^{-1}$ (palladium) and $52.6 \mathrm{mg} \mathrm{g}^{-1}$ (platinum). ${ }^{92}$ The adsorption of $\mathrm{Au}(\mathrm{III}), \mathrm{Pd}(\mathrm{II})$, and $\mathrm{Pt}(\mathrm{IV})$ onto native GO was studied $^{93}$ with an adsorption capacity of $\mathrm{Pd}(\mathrm{II})$ as $80.7 \mathrm{mg} \mathrm{g}^{-1}$. Nevertheless, to enhance the adsorption characteristics, it is essential to modify the native GO suitably. Tetraoctylammonium bromide (TOABr), a frozen ionic liquid impregnated onto graphene oxide was studied to effectively adsorb palladium with a maximum monolayer Langmuir adsorption capacity of $92.67 \mathrm{mg} \mathrm{g}^{-1}$. The cationic- $\pi$, charge interaction and electrostatic interaction were involved in the interaction mechanism. The laboratory scale column studies indicated that the method could be scaled up to larger sample volume and thiourea-HCl mixture was effective to recover palladium. The adsorbent had the potential to recover palladium in the presence of complex ions and spent catalyst. ${ }^{\mathbf{9 4}}$

5.1.3 Polymeric resins. Polymeric resins have gained huge interest in industrial applications because of their macroreticular nature. Macroporous resins were first developed in the 1960s and due to their polymeric matrix they are capable of enhancing the adsorption capacity and ease of accessing chelating sites for a range of metal ions. ${ }^{95,96}$ They are basically based on polystyrene-divinyl benzene (PSDVB) and polyacrylatedivinylbenzene (PADVB) copolymers. The most widespread kind of macroporous resin is styrene and divinylbenzene copolymer, which may be found as 'polystyrene-divinylbenzene copolymer'. Amberlite XAD resin series gifted with a polystyrene divinyl benzene matrix act as an effective support to anchor coordinating ligands due to their properties such as high surface area, porosity and higher physical and chemical stability. ${ }^{55,95}$ The 
native form of the resin does not possess any functional group fundamentally and therefore appropriate modification is needed in order to generate suitable sites which in turn would increase the interaction with metal ions. Polystyrenedivinylbenzene resins and polyacrylate-divinylbenzene resins have their own nature among which the former ones are nonpolar and hence hydrophobic, whereas the later ones are moderately polar and thus hydrophilic. In general Amberlite and Dowex based polymeric resins have surface areas close to $1000 \mathrm{~m}^{2} \mathrm{~g}^{-1}$. Also, the hyper crosslinked network has a low packing density with larger free volume and a more coherent inner surface. ${ }^{97}$

The hypercrosslinked resins consist of oxygen and chlorine containing functional groups, which are by-product residues of the crosslinking reaction. The polar functional groups on the surface of polystyrene-divinylbenzene copolymers give an enhancement of hydrophilicity and favour the adsorption of polar sorbates. ${ }^{98}$ Amberlite XAD resins (XAD-2, XAD-4, XAD-7, $\mathrm{XAD}-16$, XAD-1180 and $\mathrm{XAD}-2000$ ) are very useful for the removal of metals and its complexes. ${ }^{55}$ These resins possess surface area as high as $300-800 \mathrm{~m}^{2} \mathrm{~g}^{-1}$ with pore volume and average pore diameter between $0.9-1.5 \mathrm{~cm}^{2} \mathrm{~g}^{-1}$ and $4-9 \mathrm{~nm}$ respectively.

The usefulness of Amberlite XAD resins for the removal of metal ions was extensively reviewed by Ahmad et al..$^{99}$ Mladenova et $a l .{ }^{\mathbf{1 0 0}}$ have reviewed the utility of diverse adsorbents to recover precious metal ions such as palladium(II), gold(III) and platinum(Iv). Amberlyst-A 29 and Amberlyst-A 21 anion exchange resins were studied to adsorb palladium as its chloro-complex from acidic medium. ${ }^{101}$ Likewise, Amberlite XAD-7 customized with dimethylglyoxal bis-(4-phenyl-3-thiosemicarbazone) and glyoxal dithiosemicarbazone ${ }^{\mathbf{1 0 2}}$ also show good ability to adsorb palladium. Functionalization of Amberlite XAD-16 using 2-acetyl pyridine was explored to recover palladium from high level liquid waste. ${ }^{\mathbf{1 0 3}}$ Melamine-formaldehyde-thiourea, a chelating resin was used in the adsorption and separation of palladium(II). The adsorption capacity of the resin was found to be $15.29 \mathrm{mg} \mathrm{g}^{-1}$ at pH 4.0. ${ }^{104}$ Adsorption of palladium and platinum using polyamine functionalized polystyrene beads and nanofibers was investigated and recovery was done using $3 \%$ thiourea solution with quantitative efficiency of desorption under the optimized conditions. ${ }^{\mathbf{1 0 5}}$ $N, N, N^{\prime}, N^{\prime}$-Tetra-(2-ethylhexyl)-dithiodiglycolamide impregnated onto XAD-16 resin was investigated for palladium sorption and Freundlich isotherm model fit well with maximum sorption capacity of $29 \mathrm{mg} \mathrm{g}^{-1} \cdot{ }^{106}$ 2-Mercaptobenzothiazole attached onto an amine functionalized macroreticular Amberlite XAD-1180 resin was studied to adsorb palladium with a monolayer adsorption capacity of $50 \mathrm{mg} \mathrm{g}^{-1}$. Regeneration of the resin adsorbent was done with thiourea and the scheme was checked in recovering palladium from a spent catalyst having $5 \% \mathrm{Pd}$ on activated carbon. ${ }^{107}$

5.1.4 Silica and alumina based materials. Porous oxide materials show facile adsorption behavior for heavy metal ions. ${ }^{108}$ Silica and alumina have been studied for sequestering metal ions. ${ }^{109,110}$ These mesoporous materials are endowed with relatively low cost, good thermal, mechanical stability and higher catalytic performance. ${ }^{\mathbf{1 1 0 , 1 1 1}}$
Mesoporous silica such as SBA-15 (Santa Barbara Amorphous) has evinced more attention in recent years in view of their higher pore volumes, huge surface area and tunable pore size. ${ }^{111}$ The distinct advantage of SBA-15 above other mesoporous materials such as MCM-48 and MCM-41 is that the pore walls of silica are thicker in SBA-15 which offers greater thermal stability. ${ }^{111,112}$ In this context, $N$-propylsalicylaldiminofunctionalized SBA-15 was utilized as an adsorbent for the adsorption of $\mathrm{Co}^{2+}, \mathrm{Ni}^{2+}, \mathrm{Cu}^{2+}$, and $\mathrm{Zn}^{2+} \cdot{ }^{113}$ The mesoporous materials have more potential for the removal of metals due to the presence of relatively many surface hydroxyl groups, thereby resulting in high adsorption capacities. ${ }^{\mathbf{1 1 4}}$ Adsorption of trace quantities of palladium and gold ions from real samples using surface-modified MCM-48 and MCM-41 have been investigated. ${ }^{\mathbf{1 1 4}}$ Functionalization of inorganic SBA-15 has also been done. The thiol functionalized SBA-15 silica exhibited excellent selectivity for adsorbing $\mathrm{Hg}^{2+}$ (ref. 115) and noble metals such as $\mathrm{Pd}^{2+}$ and $\mathrm{Pt}^{2+}$ (ref. 116) from waste streams. Aminofunctionalized SBA-15 showed good adsorption ability for various metal ions such as $\mathrm{Zn}^{2+}, \mathrm{Cu}^{2+}, \mathrm{Cr}^{3+}$, and $\mathrm{Ni}^{2+} \cdot{ }^{117}$ Functionalized silica based mesoscale adsorbent was tested to recover palladium(II) efficiently from wastewater. ${ }^{118}$ An efficient, reusable and selective chelating resin, diphenyldiketone monothiosemicarbazone tailored silica gel was applied for the online separation and preconcentration of palladium ions in spiked tap water samples and catalytic converter. ${ }^{119}$ A novel macrocyclic ligand functionalized silica adsorbent shows good adsorption and selectivity towards $\mathrm{Pd}(\mathrm{II})$ in $\mathrm{HNO}_{3}$ media. Selective recovery of $\mathrm{Pd}(\mathrm{II})$ from simulated high level liquid waste of a light water reactor was performed with obtained recovery rate of more than $90 \%$. Mechanism regarding the complexation between the macrocyclic ligand and $\operatorname{Pd}(\mathrm{II})$ was

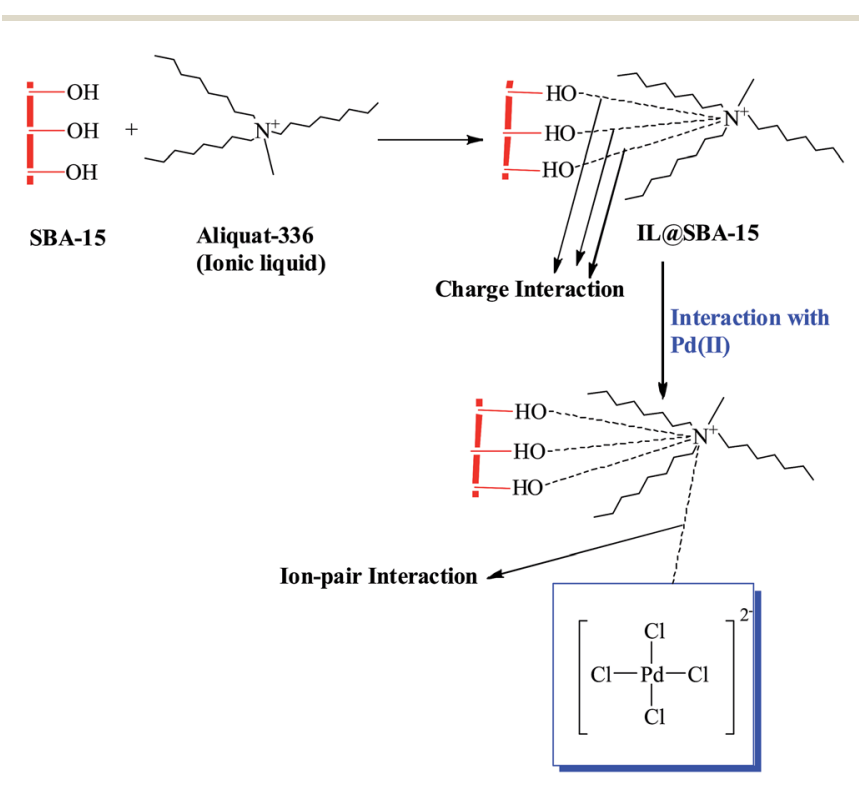

Pd-II@SBA-15

Fig. 4 Interaction mechanism of palladium with Aliquat-336 impregnated onto SBA-15 (reproduced from ref. 123 with permission of Royal Society of Chemistry). 
discussed and the maximum monolayer adsorption capacity was $83.0 \mathrm{mg} \mathrm{g}^{-1} \cdot{ }^{\mathbf{1 2 0}}$ Sabermahani et al. have reported the coating of polyethyleneimine (PEI) onto alumina and used it as an adsorbent for preconcentration and separation of palladium. The sorption capacity was found to be $13 \mathrm{mg} \mathrm{g}^{-1}$ at an optimized $\mathrm{pH}$ of 6.0 and thiourea-HCl solution was used to effectively elute adsorbed palladium from the adsorbent surface. ${ }^{\mathbf{1 2 1}}$ Alumina loaded with 5-bromo-2-pyridylazo-5-(diethylamino) phenol (5-Br-PADAP) was used for the removal of $\mathrm{Ni}(\mathrm{II})$ and Pd(II) from surface water. The obtained sorption capacities for $1.0 \mathrm{~g}$ sorbent at $\mathrm{pH} 6.0$ were $6.0 \mathrm{mg} \mathrm{Ni}(\mathrm{II})$ and $11.0 \mathrm{mg} \mathrm{Pd}(\mathrm{II})$ respectively. ${ }^{122}$ Aliquat-336, an ionic liquid impregnated onto
SBA-15 (Santa Barbara Amorphous) was investigated for the adsorption of palladium with a monolayer adsorption capacity of $212.76 \mathrm{mg} \mathrm{g}^{-1}$ and the adsorbent was regenerated using thiourea. The primary interaction involves the charge interaction of silanol groups $(\mathrm{Si}-\mathrm{OH})$ in SBA-15 with the positively charged quaternary ammonium cation of Aliquat-336. After adsorption, the tetrachloropalladate species favors ion-pair interaction with the adsorbent surface (IL@SBA-15). The effective interaction mechanism is given in Fig. 4. The continuous sorption flow studies were conducted and column efficiency was assessed using Thomas model giving an adsorption capacity of $453.89 \mathrm{mg} \mathrm{g}^{-1}$ and $376.38 \mathrm{mg} \mathrm{g}^{-1}$ at corresponding flow rates of

Table 1 Comparison of some of the selected diverse adsorbents reported in recent literature

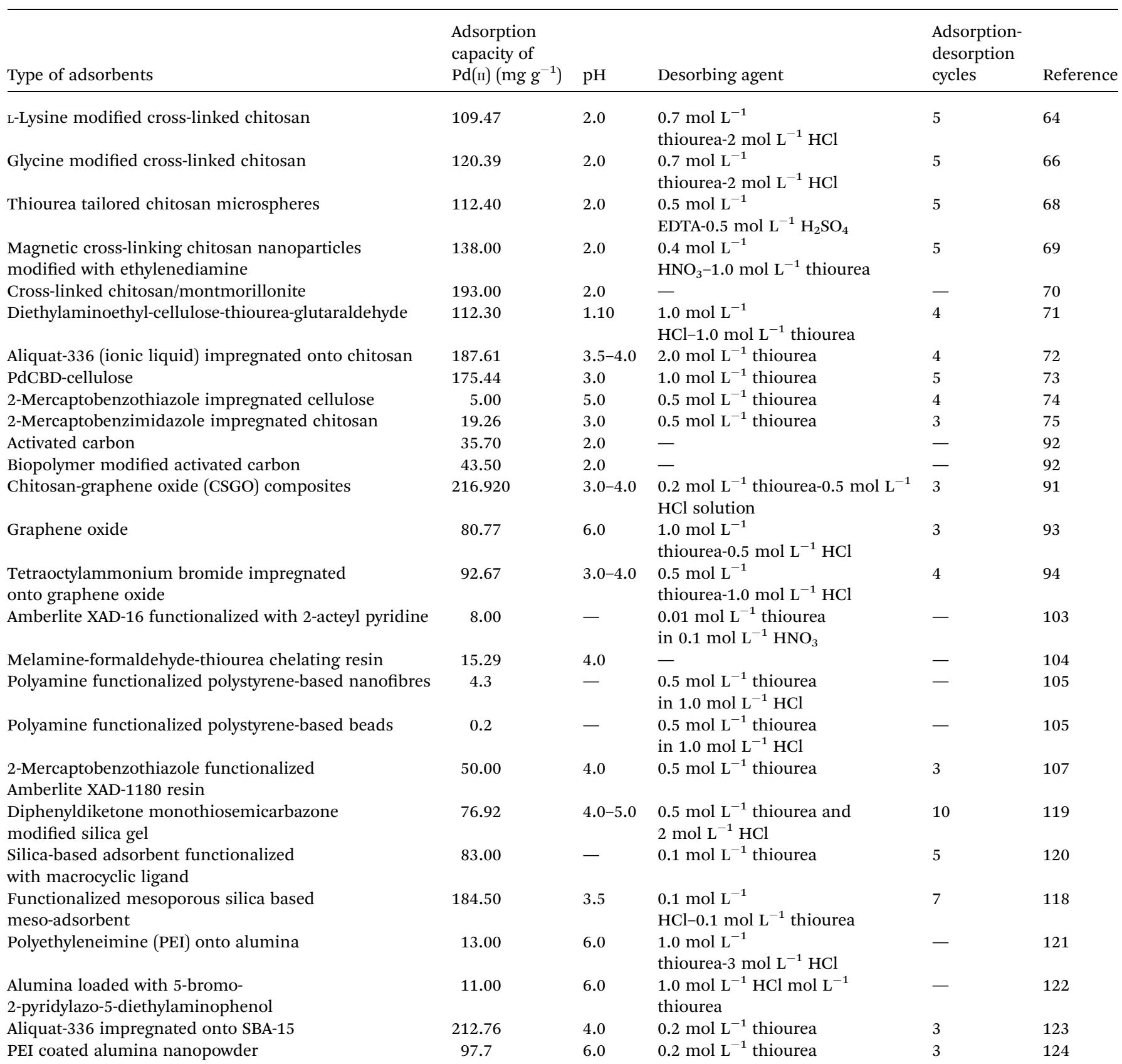


4 and $6 \mathrm{~mL} \mathrm{~min}^{-1}$. In addition, the method was tested to adsorb palladium recovered from a spent catalyst $(5 \% \mathrm{Pd}$ on activated carbon). ${ }^{123}$ More recently, amine-functionalized alumina nanopowder as an adsorbent gave a high adsorption capacity of $97.7 \mathrm{mg} \mathrm{g}^{-1}$ for palladium. This aminefunctionalized sorbent was also further tested for the catalytic reduction of 4-nitrophenol and $\mathrm{Cr}(\mathrm{vI})$ and hydrogen generation from ammonia borane. Desorption of palladium was found to be effective with a $9 \mathrm{~mL}$ volume of $0.2 \mathrm{~mol} \mathrm{~L}^{-1}$ thiourea. ${ }^{\mathbf{1 2 4}}$

\section{Conclusions and future perspectives}

The foregoing treatise on the removal and recovery of palladium exemplifies the properties such as adsorption capacity (Table 1), reusability and removal efficiency. Solid phase extraction offers certain merits over other methods in terms of treatment of higher sample volume, good analyte recovery and facile regeneration of the adsorbent. Further, it is very important to decide the selectivity of adsorbent towards the recovery of a specific metal ion. Biopolymers, polymeric resins, carbonaceous materials and silica based materials as supports can be customized or modified to extract the precious metals effectively from a complex matrix and thus yielding higher analyte retention efficacy. Incorporating nitrogen and phosphonium based ionic liquids in the above solid matrices could enhance the adsorption of palladium from chloride medium through effective electrostatic interactions. Likewise, carbon nanotubes and graphene oxide can also be modified with ionic liquids and explored for palladium recovery. The immobilization of suitably cultured microorganisms in solid supports such as resins, cellulose and silica/alumina is another prospective green option to recover palladium from spent catalysts and high level waste. Recovery of palladium from spent catalysts and liquid waste are noteworthy in practical applications. In any adsorption process, regeneration is an important parameter and reusability of adsorbents using cost-effective desorbing reagents also plays a vital role.

Adsorbent preparation using green methods such as microwave assisted and ultrasonication techniques should be explored as economically viable options ${ }^{55}$ to the conventional methods of adsorbent preparation which take more time.

The way forward should also emphasize that the novel adsorbents possess faster kinetics, high adsorption capacity, thermodynamic feasibility and regenerability for several cycles. ${ }^{55}$ On an industrial scale, the methods should be more effective to treat higher sample volumes. The involvement of the adsorbents should also serve its usefulness to recover palladium from electronic components (printed circuit boards) as well as high level nuclear waste containing palladium as the fission product. In conclusion, the road ahead offers abundant scope towards the development of novel and greener adsorbents for the recovery of palladium from diverse matrices.

\section{Conflicts of interest}

The authors declare no competing interests.

\section{References}

1 C. R. M. Rao and G. S. Reddi, Trends Anal. Chem., 2000, 19, 565 .

2 K. Ohmatsu, M. Ito, T. Kunieda and T. Ooi, Nat. Chem., 2012, 4, 473.

3 M. Yamada, M. R. Gandhi, Y. Kondo, K. Haga, A. Shibayama and F. Hamada, RSC Adv., 2015, 5, 60506.

4 P. Das and W. Linert, Coord. Chem. Rev., 2016, 311, 1.

5 M. D. Shultz, J. P. Lassig, M. G. Gooch, B. R. Evans and J. Woodward, Biochem. Biophys. Res. Commun., 1995, 209, 1046.

6 R. M. Izatt, S. R. Izatt, N. E. Izatt, K. E. Krakowiak, R. L. Bruening and L. Navarro, Green Chem., 2015, 17, 2236.

7 M. Monier, D. A. Abdel-Latif and Y. G. Abou El-Reash, J. Colloid Interface Sci., 2016, 469, 344.

8 M. Hartings, Nat. Chem., 2012, 4, 764.

9 A. Bhatnagar and M. Sillanpaa, Adv. Colloid Interface Sci., 2009, 152, 26.

10 Z. Hu, L. Lei, Y. Li and Y. Ni, Sep. Purif. Technol., 2003, 31, 13.

11 M. Soylak and M. Tuzen, J. Hazard. Mater., 2008, 152, 656. 12 R. Katal, E. Hasani, M. Farnam, M. S. Baei and M. A. Ghayyem, J. Chem. Eng. Data, 2012, 57, 374.

13 F. Veglio and F. Beolchini, Hydrometallurgy, 1997, 44, 301.

14 J. Wang, J. Li and J. Wei, J. Mater. Chem. A, 2015, 3, 18163.

15 C. R. Hammond, The Elements. Handbook of Chemistry and Physics, CRC press, 81st edn, 2004, ISBN 0-8493-0485-7.

16 R. G. Pearson, J. Am. Chem. Soc., 1963, 85, 3533.

17 S. Sharma, PhD thesis, Birla Institute of Technology and Science, Pilani, India, 2016.

18 B. D. Craig and D. S. Anderson, ASM Handbook of corrosion data, 1995.

19 R. Mozingo, Palladium Catalysts, Org. Synth., 1955, 3, 685.

20 N. Miyaura and A. Suzuki, Org. Synth., 1993, 8, 532.

21 D. R. Coulson, L. C. Satek and S. O. Grim, Inorg. Synth., 2007, 13, 121.

22 D. E. Ryan, Can. J. Chem., 1961, 39, 2389.

23 M. A. Barakat, M. H. H. Mahmoud and Y. S. Mahrous, Appl. Catal., A, 2006, 301, 182.

24 Z. Hubicki, A. Wołowicz and M. L. Leszczynska, J. Hazard. Mater., 2008, 159, 280.

25 J. Emsley, Nature's Building Blocks: An A-Z Guide to the Elements, Oxford University Press, 2011.

26 C. C. C. J. Seechurn, M. O. Kitching, T. J. Colacot and V. Snieckus, Angew. Chem., Int. Ed., 2012, 51, 5062.

27 M. Zha, J. Liu, Y. L. Wong and Z. Xu, J. Mater. Chem. A, 2014, 3, 3928.

28 Y. Jiang and D. Kim, Chem. Eng. J., 2013, 232, 503.

29 V. Polshettiwar, C. Len and A. Fihri, Coord. Chem. Rev., 2009, 253, 2599.

30 Thermodynamics and Electrified Interfaces, ed. S. Ye, K. Uosaki, A. J. Bard, E. Gileadi and M. Urbakh, Wiley-VCH, Weinheim, 2002, p. 1.

31 A. Dumas and P. Couvreur, Chem. Sci., 2015, 6, 2153. 
32 J. C. Blasko, P. D. Grimm, J. E. Sylvester, K. R. Badiozamani, D. Hoak and W. Cavanagh, Int. J. Radiat. Oncol., Biol., Phys., 2000, 46, 839.

33 P. T. Finger, A. Berson, T. Ng and A. Szechter, Int. J. Radiat. Oncol, 2002, 54, 1438.

34 S. Medici, M. Peana, V. M. Nurchi, J. I. Lachowicz, G. Crisponi and M. A. Zoroddu, Coord. Chem. Rev., 2015, 284, 329.

35 K. Ravindra, L. Bencs and R. V. Grieken, Sci. Total Environ., 2004, 318, 1.

36 J. D. Whiteley and F. Murray, Sci. Total Environ., 2003, 317, 121.

37 E. Mladenova, I. Karadjova and D. L. Tsalev, J. Sep. Sci., 2012, 35, 1249.

38 M. Ruiz, A. M. Sastre and E. Guibal, React. Funct. Polym., 2000, 45, 155.

39 R. Katal, E. Hasani, M. Farnam, M. S. Baei and M. A. Ghayyem, J. Chem. Eng. Data, 2012, 57, 374.

40 F. Veglio and F. Beolchini, Hydrometallurgy, 1997, 44, 301.

41 S. Daniel, R. S. Praveen and T. P. Rao, Anal. Chim. Acta, 2006, 570, 79.

42 G. Z. Kyzas, M. Kostoglou, N. K. Lazaridis and D. N. Bikiaris, J. Hazard. Mater., 2013, 244-245, 29.

43 X. Li, C. Zhang, R. Zhao, X. Lu, X. Xu, X. Jia, C. Wang and L. Li, Chem. Eng. J., 2013, 229, 420.

44 B. Godlewska-Żylkiewicz, B. Leśniewska, U. Gąsiewska and A. Hulanicki, Anal. Lett., 2000, 33, 2805.

45 W. Wei, C. W. Cho, S. Kim, M. H. Song, J. K. Bediako and Y. S. Yun, J. Mol. Liq., 2016, 216, 18.

46 V. T. Nguyen, J. C. Lee, A. Chagnes, M. S. Kim, J. Jeong and G. Cote, RSC Adv., 2016, 6, 62717.

47 O. Ortet and A. P. Paiva, Sep. Purif. Technol., 2015, 156, 363.

48 A. P. Paiva, G. I. Carvalho, M. C. Costa, A. M. R. Costa and C. Nogueira, Sep. Sci. Technol., 2014, 49, 966.

49 H. Narita, K. Morisaku, K. Tamura, M. Tanaka, H. Shiwaku, Y. Okamoto, S. Suzuki and T. Yaita, Ind. Eng. Chem. Res., 2014, 53, 3636.

50 A. Das, R. Ruhela, A. K. Singh and R. C. Hubli, Sep. Purif. Technol., 2014, 125, 151.

51 A. P. Paiva, G. I. Carvalho, M. C. Costa, A. M. R. Costa and C. Nogueira, Solvent Extr. Ion Exch., 2014, 32, 78.

52 Y. Huang, N. Li, Y. Li, J. Wu, S. Li, S. Chen and L. Zhu, Adv. Mater. Res., 2014, 878, 399.

53 B. R. Reddy, B. Raju, J. Y. Lee and H. K. Park, J. Hazard. Mater., 2010, 180, 253.

54 B. Swain, J. Jeong, S. K. Kim and J. C. Lee, Hydrometallurgy, 2010, 104, 1.

55 S. Kalidhasan, A. S. K. Kumar, V. Rajesh and N. Rajesh, Coord. Chem. Rev., 2016, 317, 157.

56 A. Santhana Krishna Kumar, PhD thesis, BITS-Pilani, Hyderabad campus, 2013.

57 T. P. Rao, R. S. Praveen and S. Daniel, Crit. Rev. Anal. Chem., 2004, 34, 177.

58 J. R. Dodson, H. L. Parker, A. M. García, A. Hicken, K. Asemave, T. J. Farmer, H. He, J. H. Clark and A. J. Hunt, Green Chem., 2015, 17, 1951.

59 K. Chai and H. Ji, Chem. Eng. J., 2012, 203, 309.
60 W. S. Wan Ngah and S. Fatinathan, Colloids Surf., A, 2006, 277, 241.

61 A. J. Varma, S. V. Deshpande and J. F. Kennedy, Carbohydr. Polym., 2004, 55, 77.

62 X. J. Hu, J. S. Wang, Y. G. Liu, X. Li, G. M. Zeng, Z. L. Bao, X. X. Zenga, A. W. Chena and F. Long, J. Hazard. Mater., 2011, 185, 306.

63 W. S. Wan Ngah, S. A. Ghani and A. Kamari, Bioresour. Technol., 2005, 96, 443.

64 K. Fujiwara, A. Ramesh, T. Maki, H. Hasegawa and K. Ueda, J. Hazard. Mater., 2007, 146, 39.

65 M. Ruiz, A. M. Sastre and E. Guibal, React. Funct. Polym., 2000, 45, 155.

66 A. Ramesh, H. Hasegawa, W. Sugimoto, T. Maki and K. Ueda, Bioresour. Technol., 2008, 99, 3801.

67 R. S. Juang and C. Y. Ju, Ind. Eng. Chem. Res., 1998, 37, 3463. 68 L. Zhou, J. Liu and Z. Liu, J. Hazard. Mater., 2009, 172, 439. 69 L. Zhou, J. Xu, X. Liang and Z. Liu, J. Hazard. Mater., 2010, 182, 518.

70 J. Liu, L. Zheng, Y. Li, M. Free and M. Yang, RSC Adv., 2016, 6, 51757.

71 M. H. Morcali, B. Zeytuncu, S. Akman and O. Yucel, Desalin. Water Treat., 2016, 57, 6582.

72 A. S. K. Kumar, S. Sharma, R. S. Reddy, M. Barathi and N. Rajesh, Int. J. Biol. Macromol., 2015, 72, 633.

73 I. S. Yunus and S. L. Tsai, RSC Adv., 2015, 5, 20276.

74 S. Sharma and N. Rajesh, Chem. Eng. J., 2014, 241, 112.

75 S. Sharma, M. Barathi and N. Rajesh, Chem. Eng. J., 2015, 259, 457.

76 W. Ciesielski and J. Kapusniak, J. Inclusion Phenom. Macrocyclic Chem., 2009, 64, 109.

77 M. L. Bender and M. Komiyama, Cyclodextrin Chemistry, Springer-Verlag, Berlin, 1978.

78 C. Yuan, Z. Jin and X. Li, Food Chem., 2008, 106, 50.

79 Q. Y. Chen, J. B. Xiao, X. Q. Chen, X. Y. Jiang, H. Z. Yu and M. Xu, Adsorpt. Sci. Technol., 2006, 24, 547.

80 C. B. Li, X. H. Song, S. Hein and K. A. Wang, Adsorption, 2010, 16, 85.

81 S. Sharma and N. Rajesh, J. Environ. Chem. Eng., 2017, 5, 1927-1935.

82 A. S. K. Kumar, S. S. Kakan and N. Rajesh, Chem. Eng. J., 2013, 230, 328.

83 A. K. Geim, Science, 2009, 324, 1530.

84 R. Miranda and A. L. V. D. Parga, Nat. Nanotechnol., 2009, 4, 549.

85 D. A. Dikin, S. Stankovich, E. J. Zimney, R. D. Piner, G. H. B. Dommett, G. Evmenenko, S. T. Nguyen and R. S. Ruoff, Nature, 2007, 448, 457.

86 R. K. Upadhyay, N. Soin and S. S. Roy, RSC Adv., 2014, 4, 3823.

87 M. Seredych and T. J. Bandosz, Carbon, 2007, 45, 2130.

88 S. T. Yang, S. Chen, Y. Chang, A. Cao, Y. Liu and H. Wanga, J. Colloid Interface Sci., 2011, 359, 24.

89 P. Bradder, S. K. Ling, S. Wang and S. Liu, J. Chem. Eng. Data, 2011, 56, 138.

90 J. M. You, D. Kim, S. K. Kim, M. S. Kim, H. S. Han and S. Jeon, Sens. Actuators, B, 2013, 178, 450. 
91 L. Liu, C. Li, C. Bao, Q. Jia, P. Xiao, X. Liu and Q. Zhang, Talanta, 2012, 93, 350.

92 H. Sharififard, M. Soleimani and F. Z. Ashtiani, J. Taiwan Inst. Chem. Eng., 2012, 43, 696.

93 L. Liu, S. Liu, Q. Zhang, C. Li, C. Bao, X. Liu and P. Xiao, J. Chem. Eng. Data, 2013, 58, 209.

94 S. Sharma and N. Rajesh, J. Environ. Chem. Eng., 2016, 4, 4287.

95 A. Islam, M. A. Laskar and A. Ahmad, J. Chem. Eng. Data, 2010, 55, 5553.

96 S. D. Alexandratos, Ind. Eng. Chem. Res., 2009, 48, 388.

97 M. P. Tsyurupa, V. A. Davankov and S. V. J. Rogoshin, Polym. Sci. Symp., 1974, 47, 189.

98 A. W. Trochimczuk, M. Streat and B. N. Kolarz, React. Funct. Polym., 2001, 46, 259.

99 A. Ahmad, J. A. Siddique, M. A. Laskar, R. Kumar, S. H. Mohd-Setapar, A. Khatoon and R. A. Shiekh, J. Environ. Sci., 2015, 31, 104.

100 E. Mladenova, I. Karadjova and D. L. Tsalev, J. Sep. Sci., 2012, 35, 1249.

101 Z. Hubicki and A. Wołowicz, Hydrometallurgy, 2009, 96, 159.

102 S. Hoshi, H. Fujisawa, K. Nakamura, S. Nakata, M. Uto and K. Akatsuka, Talanta, 1994, 41, 503.

103 R. Ruhela, K. K. Singh, B. S. Tomar, J. N. Sharma, M. Kumar, R. C. Hubli and A. K. Suri, Sep. Purif. Technol., 2012, 99, 36.

104 E. Birinci, M. Gülfen and A. O. Aydın, Hydrometallurgy, 2009, 95, 15.

105 O. E. Fayemi, A. S. Ogunlaja, P. F. Kempgens, E. Antunes, N. Torto, T. Nyokong and Z. R. Tshentu, Miner. Eng., 2013, 53, 256.

106 A. B. Kanagare, K. K. Singh, K. K. Bairwa, R. Ruhela, V. S. Shinde, M. Kumar and A. K. Singh, J. Environ. Chem. Eng., 2016, 4, 3357.

107 S. Sharma and N. Rajesh, Chem. Eng. J., 2016, 283, 999.
108 J. R. Bargar, G. E. Brown Jr and G. A. Parks, Geochim. Cosmochim. Acta, 1997, 61, 2617.

109 G. Gentscheva, P. Tzvetkova, P. Vassileva, L. Lakov, O. Peshev and E. Ivanova, Microchim. Acta, 2007, 156, 303.

110 A. Bhat, G. B. Megeri, C. Thomas, H. Bhargava, C. Jeevitha, S. Chandrashekar and G. M. Madhu, J. Environ. Chem. Eng., 2015, 3, 30 .

111 H. Veisi, M. Hamelian and S. Hemmati, J. Mol. Catal. A: Chem., 2014, 395, 25.

112 D. P. Serrano, G. Calleja, J. A. Botas and F. J. Gutierrez, Ind. Eng. Chem. Res., 2004, 43, 7010.

113 M. Mureseanu, A. Reiss, I. Stefanescu, E. David, V. Parvulescu, G. Renard and V. Hulea, Chemosphere, 2008, 73, 1499.

114 S. Rasalingam, R. Peng and R. T. Koodali, Appl. Catal., B, 2015, 174, 49.

115 D. P. Quintanilla, I. D. Hierro, M. Fajardo and I. Sierra, Microporous Mesoporous Mater., 2006, 89, 58.

116 T. Kang, Y. Park and J. Yi, Ind. Eng. Chem. Res., 2004, 43, 1478.

117 X. Wang, K. S. K. Lin, J. C. C. Chan and S. Cheng, J. Phys. Chem. B, 2005, 109, 1763.

118 M. R. Awual, M. A. Khaleque, Y. Ratna and H. Znad, J. Ind. Eng. Chem., 2015, 21, 405.

119 R. K. Sharma, A. Pandey, S. Gulati and A. Adholeya, J. Hazard. Mater., 2012, 209-210, 285.

120 F. Bai, G. Ye, G. Chen, J. Wei, J. Wang and J. Chen, Sep. Purif. Technol., 2013, 106, 38.

121 F. Sabermahani and M. A. Taher, J. Anal. At. Spectrom., 2010, 25, 1102.

122 F. Sabermahani, M. Saeidi and V. Sharifzade, Bull. Chem. Soc. Ethiop., 2013, 27(1), 15.

123 S. Sharma, C. M. Wu, R. T. Koodali and N. Rajesh, RSC Adv., 2016, 6, 26668.

124 R. Nagarjuna, S. Sharma, N. Rajesh and R. Ganesan, ACS Omega, 2017, 2, 4494. 